\title{
PRIMARY NON-GESTATIONAL CHORIOCARCINOMA OF OVARY (NGCO)
}

K. Venkatram Reddy ${ }^{1}$, Padmalatha², M. James Premsagar ${ }^{3}$, Praveen ${ }^{4}$, Aarthi Reddy ${ }^{5}$

\section{HOW TO CITE THIS ARTICLE:}

K. Venkatram Reddy, Padmalatha, M. James Premsagar, Praveen, Aarthi Reddy. "Primary Non-Gestational Chorioc-arcinoma of Ovary (NGCO)". Journal of Evolution of Medical and Dental Sciences 2015; Vol. 4, Issue 30, April 13; Page: 5246-5250, DOI: 10.14260/jemds/2015/768

ABSTRACT: Non-gestational choriocarcinoma of the ovary is an extremely rare tumour, which occurs usually in the reproductive age groups. It is extremely difficult to diagnose as it often mimics torsion ovarian cyst, Ectopic pregnancy etc. As choriocarcinoma alone is extremely a rare entity, thorough search for uterine or tubal organs should be undertaken we present a case of 18 year old girl having non - gestational primary ovarian choriocarcinoma.

KEYWORDS: Non - gestational primary ovarian choriocarcinoma, DNA polymorphism, BETA-hcg.

INTRODUCTION: Para primary ovarian choriocarcinoma is a rare entity.(1) It can be either gestational or non-gestational in origin. But most are gestational in origin and usually metastasize to ovary from uterine or tubal choriocarcinoma.(1)

Non-gestational choriocarcinoma of the ovary usually presents as mixed germ cell tumour, where as pure non - gestational choriocarcinoma is rare and difficult in diagnosing and have worst prognosis. We present this because of its rarity.

CASE REPORT: 18 years old female, comes with a complaint of continuous bleeding for 20 days, with pain in the lower abdomen along with associated generalized weakness. There is no past history of abortion/normal pregnancy. On examination pulse rate 80/min, RR -normal range, on auscultation no murmurs, blood pressure is normal and patient is co-operative and coherent.

\section{INVESTIGATIONS:}

ULTRASONOGRAPHY: A large round to ovoid well defined mass lesion with mixed soft tissue echogencity with large central anoechoic areas representing necrosis in the right adnexa abutting the anterior wall of the uterus causing mass effect over the uterus as it arises out of the pelvis to be in the region of the right flank. The space occupying lesion measures $20 \times 6 \mathrm{~cm}$ in size.

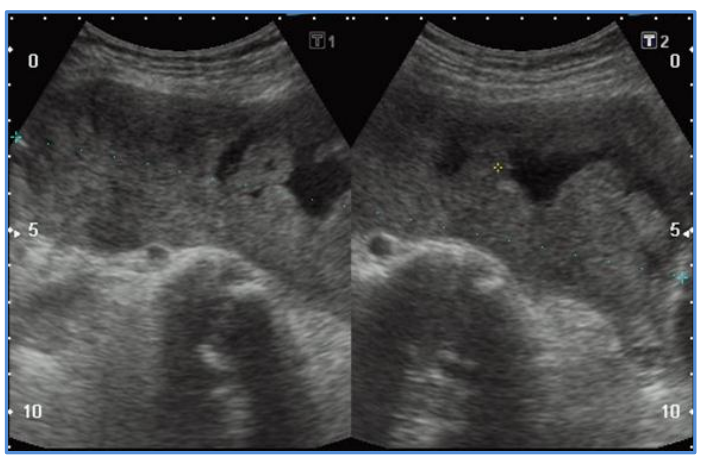




\section{CASE REPORT}

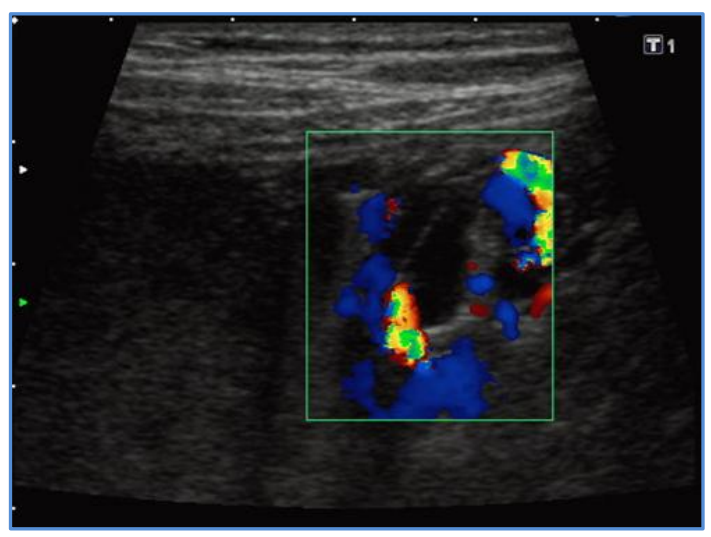

A similar well defined soft tissue echogencity nodule attached to the peritoneum in the periumbilical region was noted which indicated peritoneal metastasis.

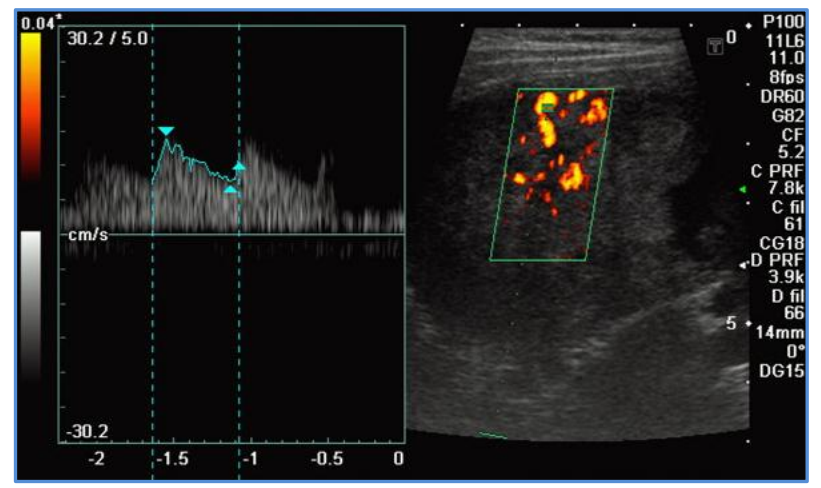

The SOL shows increased colour flow on Doppler examination. Its resistive index was 0.4 suggesting the malignant nature of the lesion which probably ovarian in origin. No significant ascitis is noted.

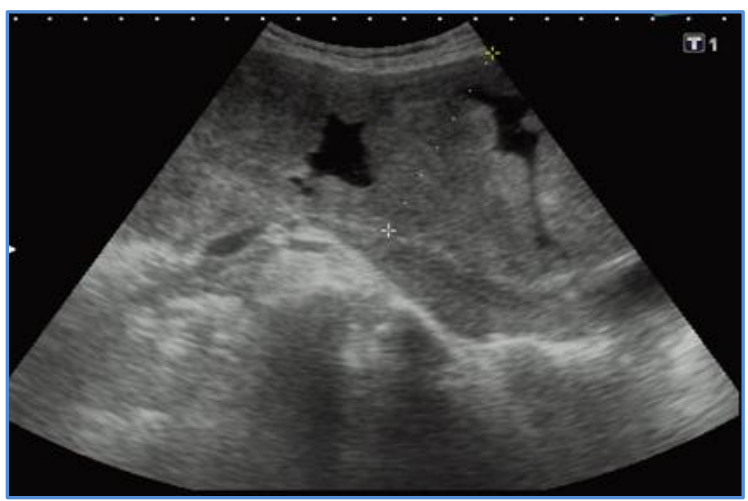




\section{COMPUTER TOMOGRAPHY:}

As the above findings are confirmed with NECT scan.

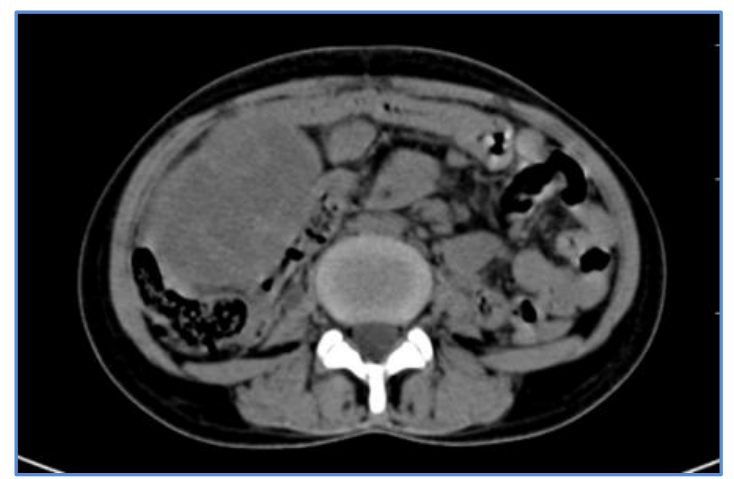

NECT revealed a right latero - uterine mass without fat stranding and shows few hypodense areas of necrosis.

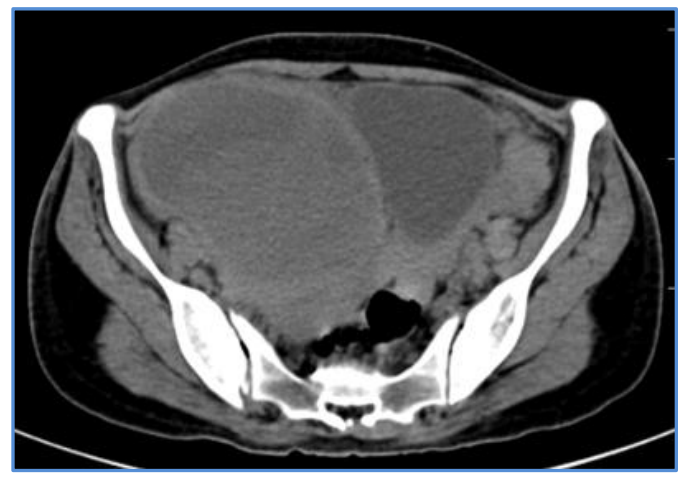

The above findings further supported by raised Beta - Human choriogonadotrophin hormone values (B - HCG: 62, $144 \mathrm{IU} / \mathrm{ML})$. $^{(2)}$

INTRA OPERATIVE HPE SPECIMEN: Sections taken from various parts of the tumoral mass show structures of ovary with stroma along with corpus luteum.

Sections also show tumour area with tumour cells that are large pleomorphic round to polygonal with hyperchromatic and vesicular type type of nuclei also seen are few tumor giant cells.

No other germ cell was detected.

Peritoneal surface deposits showed metastatic cells.

There are extensive areas of necrosis and hemorrhage.

The diagnostic criteria used to diagnose. Non gestational choriocarnoma which were first described by SAITO. et. al are mentioned below. (3)

1. Absence of disease in the uterine cavity.

2. Pathological confirmation of the disease.

3. Exclusion of molar pregnancy.

4. Exclusion of coexistence of intra uterine pregnancy. 
DISCUSSION: Non-gestational ovarian choriocarcinoma is extremely rare accounts for nearly $0.6 \%$ or less of all ovarian neoplasms with 50 cases in the world literature and age is usually below $<20$ years.(1) It may be associated with other germ cell tumours like immature teratoma, endodermal sinus tumour, embryonal carcinoma and dysgerminoma. Elevated serum hcg is $100 \%$ sensitive and $100 \%$ specific. It is usually unilateral and predominantly solid vascular tumour with areas of hemorrhagic \& necrosis and with cyst formation. It is important to distinguish between gestational choriocarcinoma and the ovary involved and non - gestational choriocarcinoma because of the poor prognosis.

Diagnosis of pure non-gestational choriocarcinoma is uncertain without(4,5) D.N.A polymerization analysis and genetic analysis must be a useful tool in determining the diagnosis of the choriocarcinoma. Since D.N.A polymorphism analysis is not generally available laboratory technique we could not perform in our case.

DNA analysis can also be use evaluate any hereditary-paternal to establish the diagnosis of NGCO.(6)

SUMMARY: In summary the highly vascularised nature of the mass, the presence of multiple cystic cavities in the solid portion and central hemorrhagic and necrotic changes with high B - hcg levels and an empty sterns \& fallopian tubes, suggestive of a non-gestational ovarian carcinoma (Choriocarcinoma).

\section{REFERENCES:}

1. Jacobs AJ, Newland JR, Green RK. Pure Choriocarcinoma of the ovary. Obstet. Gynecol of Surv 1932:37:603 - 9 .

2. Atlas of heretics - Cytogenetics in oncology \& cytogenetics, April 2015.

3. SAITO et.al (Saito M, Azuma T, Nakanura K), on Ectopic choriocarcinoma Journal 1963:17:459 484.

4. TSUJIOKA H, Hamada H, Miyakawa T, Hachissuga T, Kawaraboyashi T, A pure Non - gestational choriocarcinoma of the ovary diagnosed with DNA polymorphism analysis. Gynecol Oncol: 2003:89(3)540 - 2 (pub med).

5. Yamamoto E, Ino K, Yamamoto T, Sumigama S, Nawa A, Nomura S, A pure Non - gestational choriocarcinoma of the ovary diagnosed with short tandem repeat analysis; case report and review: Int.J.Gynecol cancer 2007: (17), 254 - 258 (pub med).

6. Koo HL, Choij, Kim KR, Kim SH, Pure Non - gestational choriocarcinoma of the overy diagnosed by DNA polymorphism analysis. Int. Jr. Pathology 2006, 56 (10): 613 - 616.

7. Balat O, Kutlar I, Ozkur A, Bakir K, Aksoy F, Ugur MG: Primary pure ovarian choriocarcinoma mimicking ectopic pregnancy; a report of fulminant progression Tumori 2004; 90:136 - 138 (pub med).

8. Gyncologic tumours and symptoms in child hood and adolescence Curr. Opin. Obst gynecology 2005; 13: 469 - 473 (pub med). 


\section{AUTHORS:}

1. K. Venkatram Reddy

2. Padmalatha

3. M. James Premsagar

4. Praveen

5. Aarthi Reddy

\section{PARTICULARS OF CONTRIBUTORS:}

1. Professor and HOD, Department of Radiology, SVS Medical College and Hospital, Yenugonda, Mahabubnagar.

2. Professor, Department of Obstetrics and Gynaecology, SVS Medical College and Hospital, Yenugonda, Mahabubnagar.

3. Assistant Professor, Department of Radiodiagnosis, SVS Medical College and Hospital, Yenugonda, Mahabubnagar.

FINANCIAL OR OTHER

COMPETING INTERESTS: None
4. Final Year Post Graduate, Department of Radiology, SVS Medical College and Hospital, Yenugonda, Mahabubnagar.

5. Final Year Post Graduate, Department of Radiology, SVS Medical College and Hospital, Yenugonda, Mahabubnagar.

\section{NAME ADDRESS EMAIL ID OF THE} CORRESPONDING AUTHOR:

Dr. M. James Premsagar, Assistant Professor, Department of Radiology, SVS Medical College and Hospital, Yenugonda, Mahabubnagar-509001.

E-mail: premsvsraddoc@gmail.com

Date of Submission: 13/03/2015.

Date of Peer Review: 14/03/2015.

Date of Acceptance: 01/04/2015.

Date of Publishing: 13/04/2015. 